\title{
Court case blows away US-French truce on industrial espionage allegations
}

Paris. Allegations by the US company Texas Instruments $(\mathrm{TI})$ that technology stolen by French spies ended up on a patent awarded to the computer company Bull have reopened the simmering row between the United States and France on industrial espionage.

The French state-owned computer company fired the first shot in this latest dispute - revealed last week by the French magazine $L$ 'Express - by suing TI for infringing a 1983 Bull patent for a chip designed to process confidential information. But TI's return fire sent the patent lawyers diving for cover: the patent, it said, was based on TI technology "unlawfully expropriated by one or more agents of the French government covertly placed within TI... to obtain technical information for Compagnie des Machines Bull".

Bull seems to be asking for a thrashing. Even if its claims about the 1983 patent are valid, TI is well positioned to support its allegations of spying. In 1989 the US Federal Bureau of Investigation (FBI) and the Central Intelligence Agency (CIA) identified a senior TI employee as a French spy, confirms Maurice Botbol, publisher of the Paris-based "Intelligence Newsletter".

The employee, identified only by the code-name "MD", was part of an elaborate programme set up by France following the election of François Mitterrand as president in 1981. Pierre Marion, then head of the French external security service, sought out industrial and technological targets, and began recruiting large numbers of "honourable correspondents" within foreign companies. The practice then - and probably now, he has said - was to pass on information to French companies.

The French and US governments will be less concerned by who owns the patent than by the risk that the dispute could undermine their agreement not to accuse each other of spying in public, says Botbol. Under the terms of this partial truce - intended to prevent souring of diplomatic relations, and keep the way clear for cooperation against terrorism and nuclear proliferation - neither side has agreed to stop economic spying, he says, but they have agreed not to go beyond what is "tolerable".

The arrest of the TI employee along with a network of French spies implanted in other US technology companies in 1989 was quickly followed by a meeting between senior US intelligence officials and the head of the French secret service, Claude Silberzahn. France, caught red-handed, owned up, promised not to do it again, and managed to avoid any real sanction.

Last year, secret services from the two countries signed a fresh "non-aggression" pact. This followed French dismay after the US company Hughes Aircraft, acting on information from the CIA, withdrew from the Paris Air Show because of the threat of espionage. French observers allege that the CIA fabricated the threat partly to discredit the air show, and partly to persuade Congress that the CIA was still worth funding, despite the collapse of the Soviet threat.

Truce or no truce, TI seems determined to fight off Bull's patent challenge in the courts. According to L'Express, the company has already asked Bull to supply documents which it claims reveal its relations with the French secret service, and would demand that "MD" stand as a witness. Neither company is willing to comment either on the court case or the background to it. But observers predict that somehow the matter will be taken down a long dark alley and quietly smothered.

Industrial espionage now accounts for two-thirds of all spying, according to the French counter-espionage service. IBM Europe describes espionage as a "continuing problem". One US agency has estimated that such spying costs the US economy $\$ 100$ billion annually, while the figure in France has been estimated at FF25 billion.

More prosaically, some French companies complain that the intelligence services are not collecting enough of the right sort of information, and that it is not equitably distributed between them. For their part, the counter-espionage agencies are campaigning to persuade French companies and laboratories to take more precautions. Even the French biomedical research organization INSERM recently warned its researchers of the growing risks of espionage arising from the internationalization of science and its growing strategic importance (see Nature 367,587 ; 1994).

Declan Butler

\section{Wyden widens net of probe into drug marketing}

San Francisco. A subcommittee of the United States Congress is widening its investigation into allegedly fraudulent marketing activities at the Californian biotechnology company Genentech to include Eli Lilly and other pharmaceutical companies.

Three federal agencies and the House of Representatives subcommittee on small business regulation chaired by Ron Wyden (Democrat, Oregon) have been investigating the marketing and promotion of Protropin, Genentech's human growth hormone.

Steve Jenning, staff director for the subcommittee, says the lawmakers are asking the agencies to look at "unsettling evidence" that marketing and research improprieties are common throughout the industry. Jenning thinks that new drug marketing techniques blur the lines between marketing and research: research grants, direct reimbursements for prescribing doctors and cash in- centives are all problems, he says. The committee has written to Genentech and Eli Lilly requesting information about their research into human growth hormone.

On 23 August, the Inspector General of the Food and Drug Administration issued a special fraud alert warning that many drug companies are illegally going beyond traditional advertising and education. They are illegally offering valuable benefits to physicians, suppliers and, increasingly, patients, in exchange for selecting specific prescription drug brands, the notice said. The warning mentions not only prizes and cash or gifts offered for prescriptions, but also grants to physicians and clinicians for studies of questionable scientific merit.

In the case of Genentech, regulators are inquiring into alleged bribes for prescribing its human growth hormone; marketing for short stature; and promotional activities by a nonprofit foundation that
Genentech helps to fund.

This week the Foundation on Economic Trends, a pressure group led by Jeremy Rifkin, called on the Drug Enforcement Agency to prosecute doctors who prescribe human growth hormone to children who are not growth-hormone deficient. The group based its request on a law that prohibits sale of the hormone for anything other than the treatment of a recognized medical condition.

Rifkin also contends that Genentech both directly and indirectly funded height-screening programmes in hospitals and four US school districts to help draw new patients. Genentech defended its efforts to fund research on short-stature children. "All doctors are highly trained, highly intelligent people who are able to make judgements on their own," says a company spokesman, adding that pharmaceutical funding would not wash their integrity away.

Sally Lehrman 